\title{
Vitamin D level and extent of coronary stenotic lesions in patients with first acute myocardial infarction
}

\author{
Beata Goleniewska, Michał Kacprzak, Marzenna Zielińska \\ Intensive Cardiac Therapy Clinic, Medical University of Lodz, Lodz, Poland
}

\begin{abstract}
Background: The study aimed to examine the relationship between vitamin D levels and the extent of coronary stenotic lesions in patients with $S T$-segment elevation myocardial infarction (STEMI). Experimental evidence points to the involvement of multiple factors in coronary plaque formation, including vitamin D. Little is known, however, about the association of vitamin D level with the intensity of atherosclerosis.

Methods: Serum concentrations of 25-hydroxyvitamin D [25(OH)D] were measured in 130 consecutive patients with the first acute STEMI treated with primary percutaneous coronary intervention. STEMI was the first symptom of coronary artery disease (CAD). The study population was divided into patients with single and multi-vessel $C A D$. The angiographic severity of CAD was also determined based on the Gensini score.

Results: The median 25(OH)D concentration was $11.12 \mathrm{ng} / \mathrm{mL}\left(25^{\text {th }}\right.$ and $75^{\text {th }}$ percentile: 6.05; 17.12). Insufficient (20-30 $\mathrm{ng} / \mathrm{mL})$, deficient $(10-20 \mathrm{ng} / \mathrm{mL})$ and severely deficient $(<10 \mathrm{ng} / \mathrm{mL}) 25(\mathrm{OH})$ D levels were present in 18\%, 35\% and 45\% of the individuals, respectively. Only 2 (2\%) of patients had proper 25(OH)D levels (> $30 \mathrm{ng} / \mathrm{mL}$ ). The $25(\mathrm{OH}) \mathrm{D}$ concentrations between patients with single-and multi-vessel CAD did not differ significantly (10.2 vs. $11.4 \mathrm{ng} / \mathrm{mL}, p=0.62$ ). There was no significant correlation between 25(OH)D levels and Gensini score $(r=-0.0221, p=0.81)$.

Conclusions: The study demonstrated that vitamin D level is not associated with the severity of coronary lesions in patients with the first STEMI. A high prevalence of vitamin D deficiency in these patients was confirmed. (Cardiol J 2014; 21, 1: 18-23)
\end{abstract}

Key words: vitamin D, coronary angiogram, acute myocardial infarction, coronary artery disease

\section{Introduction}

Cardiovascular disease (CVD) remains the leading cause of death in the developed world. Atherosclerosis, the principal cause of myocardial infarction (MI) and cerebral infarction, accounts for the majority of these deaths. The pathogenesis of atherosclerosis has not yet been well elucidated. Experimental evidence points to the involvement of multiple factors in plaque formation, including vitamin D.

Vitamin D has an established role in calcium homeostasis, bone mineralization and regulation of parathyroid hormone secretion; accumulated knowledge has further revealed a broad distribution of vitamin D receptors, that includes: cardiovascular, musculoskeletal, gastrointestinal, immune, central nervous system, endocrine organs and others [1].

Address for correspondence: Beata Goleniewska, MD, Intensive Cardiac Therapy Clinic, Medical University of Lodz, ul. Sterlinga 1/3, 91-425 Łódź, Poland, tel/fax: +48 4266443 64, e-mail address: bgoleniewska@op.pl 
Hypovitaminosis D could participate in the pathogenesis of several diseases. Epidemiological studies have demonstrated the independent association between vitamin D deficiency and CVD risk factors, such as hypertension [2], diabetes mellitus [3], obesity [4], metabolic syndrome [5], subclinical atherosclerosis (intima-media thickness [IMT]) [6], and coronary calcification [7, 8]. Hypovitaminosis D has also been associated with cardiovascular events, such as MI [9], congestive heart failure, sudden cardiac death [10] and total mortality [11].

Vitamin D has potential ameliorating effects on the development of atherosclerosis by several mechanisms, but the molecular mechanisms of this association remain not completely understood. Serum levels of vitamin $\mathrm{D}$ seem to be inversely associated with the extent of vascular calcifications, which are frequently found in patients with CVD. Vitamin could protect against atherosclerosis and vascular calcification by its inhibiting effect on vascular smooth muscle cells proliferation. It directly or indirectly regulates the expression of a number of proteins relevant to the arterial wall, such as vascular endothelial growth factor, matrix metalloproteinase type 9, elastin, and type I collagen. Probably, vitamin D has also an impact on the cardiovascular system by exerting anticoagulant and antifibrotic activity [12], thereby preventing thrombosis.

Accumulated evidence indicates that atherosclerosis is an autoimmune disease [13]. Vitamin D could also be associated with CVD by down-regulating pro-inflammatory cytokines (tumor necrosis factor [TNF- $\alpha$ ] and interleukin [IL-6]) and up-regulating anti-inflammatory cytokines (IL-10) [14-16]. The study revealed that a reduction in atherosclerotic lesion formation resulted from the suppression of immune reactions, with at least 2 cell types crucially involved in vitamin D3 effects (regulatory T cells and dendritic cells) [17]. Because hypovitaminosis D is easily correctable, establishing the relationship between vitamin $\mathrm{D}$ and the risk of atherosclerosis is very important.

Little is known, however, about the association of vitamin $\mathrm{D}$ with the intensity of atherosclerosis. A few studies have focused on this problem in patients with acute coronary syndrome. The aim of the this study was therefore to determine both the vitamin $\mathrm{D}$ level and its association with the extent of coronary stenotic lesions in patients with acute MI.

\section{Methods}

\section{Study population}

The study involved a group of 130 consecutive patients, Caucasian in origin, aged $>18$ years, and admitted to our hospital due to the first acute ST-segment elevation MI (STEMI) treated with primary percutaneous coronary intervention (pPCI). STEMI was the first symptom of coronary artery disease (CAD). The study was performed within 2 years (2010-2011) during summer (June, July) and winter (November, December) months when there is the highest and lowest sun exposure.

Patients with a history of malignancy within the past 5 years, abnormal liver or renal function (serum aminotransferase activity $>40 \mathrm{IU} / \mathrm{L}$, glomerular filtration rate $[\mathrm{GFR}]<60 \mathrm{~mL} / \mathrm{min} / 1.72 \mathrm{~m}^{2}$ ), thyroid or parathyroid disease, sarcoidosis, tuberculosis, rickets type I, II, III, hypophosphatemic rickets, nephrotic syndrome, autoimmune disease, were excluded from the study.

Baseline characteristics were obtained for all patients. We recorded demographic information, cardiovascular history, risk factors (hypercholesterolemia, smoking, hypertension and diabetes mellitus), and prior embolic events. Acute STEMI was defined according to consensus documents of the American College of Cardiology and the European Society of Cardiology [18]. Within 90 min of admission, all patients had coronary angiography with subsequent $\mathrm{pPCI}$ performed. Standard concomitant therapy (aspirin, thienopyridines, beta-blockers, ACE-inhibitors, statins) was administered in all eligible patients.

The angiographic severity of CAD was determined based on the Gensini score [19]. The Gensini score was calculated for each patient from the coronary arteriogram by assigning a severity score to each coronary stenosis according to the degree of luminal narrowing and its geographic importance. Reduction in the lumen diameter, and the roentgenographic appearance of concentric lesions and eccentric plaques were evaluated (reductions of 25\%, 50\%, 75\%, 90\%, 99\%, and complete occlusion were given Gensini scores of $1,2,4,8,16$, and 32 , respectively). Each principal vascular segment was assigned a multiplier in accordance with the functional significance of the myocardial area supplied by that segment: the left main coronary artery $\times 5$; the proximal segment of left anterior descending coronary artery (LAD) $\times 2.5$; the proximal segment of the circumflex artery $\times 2.5$; the mid-segment of the LAD $\times 1.5$; the right coronary artery, the distal segment of the LAD, the posterolateral artery and the obtuse marginal artery $\times 1$; and others $\times 0.5$.

Independently, the study population was divided into patients with single and multi-vessel CAD. Angiographic single - and vessel CAD was defined as the occurrence of one critical stenosis 
Table 1. Baseline characteristics of study population.

\begin{tabular}{|c|c|c|c|}
\hline & Single-vessel CAD $(n=65)$ & Multi-vessel CAD (n = 65) & $\mathbf{P}$ \\
\hline Age [years] & $58[52 ; 67]$ & $61.5[56 ; 71]$ & 0.06 \\
\hline Male & $46(70.8 \%)$ & $43(66.2 \%)$ & 0.57 \\
\hline Body mass index $\left[\mathrm{kg} / \mathrm{m}^{2}\right]$ & $25.9[24.2 ; 34.1]$ & $27.6[25 ; 30.5]$ & 0.42 \\
\hline Diabetes & $10(15.4 \%)$ & $23(35.4 \%)$ & 0.009 \\
\hline Hypertension & $32(49.2 \%)$ & $44(67.7 \%)$ & 0.03 \\
\hline Current smokers & $42(64.6 \%)$ & $33(50.8 \%)$ & 0.10 \\
\hline Systolic BP [mm Hg] & $130[115 ; 150]$ & $130[110 ; 140]$ & 0.72 \\
\hline Diastolic BP [mm Hg] & $80[70 ; 85]$ & $80[70 ; 80]$ & 0.75 \\
\hline Total cholesterol [mmol/L] & $5.2[4.6 ; 5.9]$ & $5.5[4.4 ; 6.3]$ & 0.36 \\
\hline $\mathrm{HDL}-\mathrm{C}[\mathrm{mmol} / \mathrm{L}]$ & $1.3[1.1 ; 1.5]$ & $1.3[1.1 ; 1.5]$ & 0.58 \\
\hline LDL-C [mmol/L] & $3.2[2.4 ; 3.6]$ & $3.2[2.4 ; 3.9]$ & 0.51 \\
\hline Triglycerides [mmol/L] & $1.4[1.2 ; 2.1]$ & $1.5[1 ; 2.3]$ & 0.80 \\
\hline $25(\mathrm{OH}) \mathrm{D}[\mathrm{ng} / \mathrm{mL}]$ & $10.2[5.3 ; 16.7]$ & $11.4[6.3 ; 17.9]$ & 0.62 \\
\hline $\mathrm{Hs}-\mathrm{CRP}[\mathrm{mg} / \mathrm{L}]$ & $4.0[1.1 ; 15]$ & $5.2[2.2 ; 13.9]$ & 0.37 \\
\hline Ejection fraction [\%] & $50[45 ; 54]$ & $49[43 ; 55]$ & 0.74 \\
\hline \multicolumn{4}{|l|}{ Final MI diagnosis: } \\
\hline Infero-posterior & $30(46.2 \%)$ & $27(41.5 \%)$ & 0.6 \\
\hline Antero-lateral & $35(53.8 \%)$ & $38(58.5 \%)$ & 0.6 \\
\hline Troponin T [ng/mL] & $2.8[0.7 ; 6]$ & $2.9[0.9 ; 5.3]$ & 0.93 \\
\hline Gensini score & $34[32 ; 48]$ & $66[46 ; 86]$ & 0.000001 \\
\hline
\end{tabular}

Data are median [interquartile range] or numbers (percentages); CAD — coronary artery disease; BP — blood pressure; HDL-C — high density lipoprotein cholesterol; LDL-C — low density lipoprotein cholesterol; 25(OH)D - 25-hydroxyvitamin D; hs-CRP — high sensitivity C-reactive protein; $\mathrm{Ml}$ - myocardial infarction

of at least $70 \%$ in a major coronary artery (anterior descending coronary artery, right coronary artery, circumflex coronary artery) estimated by visual analysis. By analogy, multi-vessel CAD was defined as the occurrence of more than one critical stenosis of at least $70 \%$ in a major coronary artery and/or of at least $50 \%$ in the left main coronary artery.

Serum concentrations of 25 -hydroxyvitamin D $[25(\mathrm{OH}) \mathrm{D}]$ were measured in the research laboratory using a electrochemiluminescence immunoassay method (ECLIA Roche diagnostics, Mannheim, Germany). Blood samples were obtained by venipuncture in the morning the day after coronary angiography and placed into tubes that were protected from sunlight. Serum was separated and stored at $-70^{\circ} \mathrm{C}$ within $30 \mathrm{~min}$ of collection. Participants were classified into clinically-relevant categories on the basis of $25(\mathrm{OH}) \mathrm{D}$ levels. Patients with levels $\geq 30 \mathrm{ng} / \mathrm{mL}$ were classified as normal, while levels $>20 \mathrm{ng} / \mathrm{mL}$ and $<30 \mathrm{ng} / \mathrm{mL}$ were considered insufficient. Levels of $>10 \mathrm{ng} / \mathrm{mL}$ to $\leq 20 \mathrm{ng} / \mathrm{mL}$ were deficient, and levels $\leq 10 \mathrm{ng} / \mathrm{mL}$ were severely deficient, according to current clinical guidelines [20].
The study was approved by the local bioethical committee and all patients gave their informed consent.

\section{Statistical analysis}

Continuous variables were summarized by median values with corresponding $25^{\text {th }}$ and $75^{\text {th }}$ percentiles (Q25 and Q75). Discrete variables were summarized in terms of frequencies and percentages. Comparisons between groups were made using the Whitney-Mann test and Pearson's $\chi^{2}$ analysis for continuous and categorical variables, respectively. Correlations between continuous variables were determined by Spearman's correlation coefficients. Multiple logistic regression analysis was used to identify independent predictors of multi-vessel CAD. P-value of $<0.05$ was considered statistically significant. All analyses were performed using Statistica 10.0 (StatSoft Inc., USA).

\section{Results}

Clinical and biochemical characteristics of the group are shown in Table 1. 


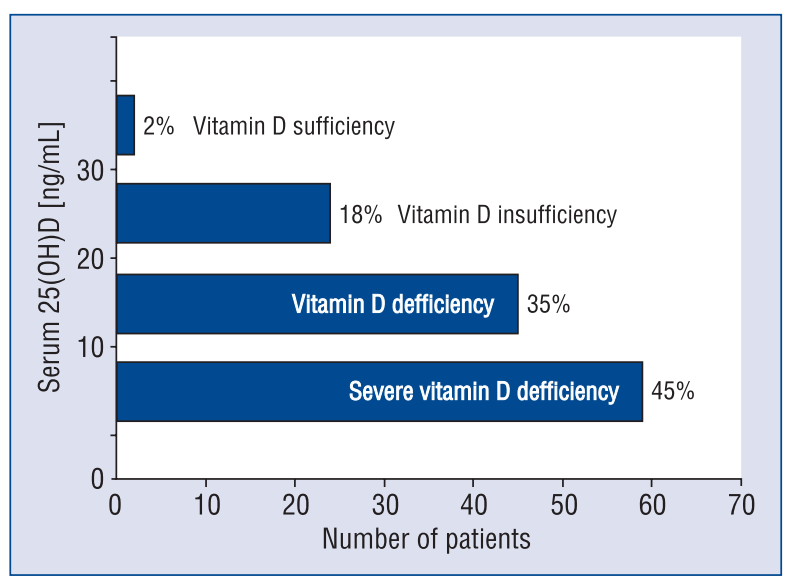

Figure 1. Distribution of vitamin $D$ concentrations in patients with acute myocardial infarction; 25(OH)D 25-hydroksyvitamin D; sufficiency - 25(OH)D concentration $\geq 30 \mathrm{ng} / \mathrm{mL}$, deficiency $-25(\mathrm{OH}) \mathrm{D}$ concentration $<30 \mathrm{ng} / \mathrm{mL}$.

Of the 130 enrolled patients, the median $25(\mathrm{OH}) \mathrm{D}$ concentration was $11.12 \mathrm{ng} / \mathrm{mL}\left(25^{\text {th }}\right.$ and $75^{\text {th }}$ percentile: $\left.6.05 ; 17.12\right)$. Classification of $25(\mathrm{OH}) \mathrm{D}$ levels into presented ranges showed $59(45 \%)$ patients to be severely deficient, $45(35 \%)$ to be deficient and $24(18 \%)$ to be insufficient. Only $2(2 \%)$ study participants had proper 25(OH)D levels (Fig. 1). Low 25(OH)D levels were observed during both summer (June, July) and winter (November, December) months. However, in patients hospitalized in the summertime the $25(\mathrm{OH}) \mathrm{D}$ concentration was slightly higher than in patients hospitalized in the wintertime (12.4; Q25 8.1; Q75 19.2 vs. 9.1; Q25 4.9; Q75 $17.0 \mathrm{ng} / \mathrm{mL}$; $\mathrm{p}=0.034$ ) (Fig. 2).

Single-vessel CAD was diagnosed in 65 (50\%) patients. In our study we did not find any significant association between 25(OH)D concentrations and incidence of single and multi-vessel CAD. More often, patients with multi-vessel disease had diabetes and hypertension. Regarding body mass index (BMI), total cholesterol, HDL-cholesterol, LDL-cholesterol, triglycerides, calcium, intact parathyroid hormone, phosphate, creatinine, eGFR, high sensitivity $\mathrm{C}$-reactive protein, there was no significant difference in those with single-vessel CAD or multi-vessel CAD.

The Gensini score ranged from 0 to 134 with a median of $48\left(25^{\text {th }}\right.$ and $75^{\text {th }}$ percentile: $\left.32 ; 80\right)$. There was no significant correlation between 25(OH)D levels and Gensini score $(r=-0.0221$, $\mathrm{p}=0.81$; Fig. 3 ).

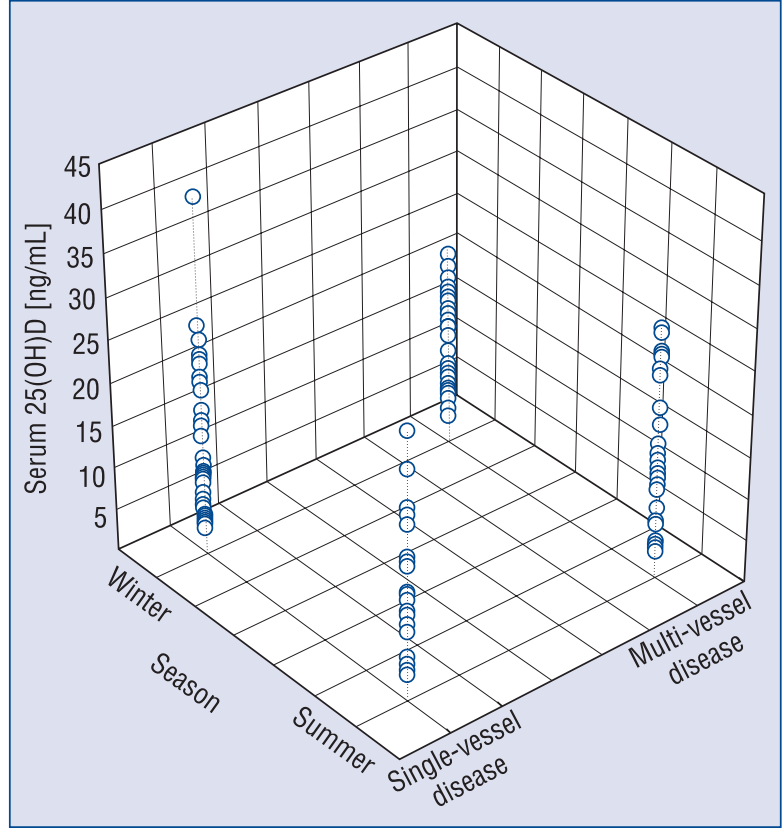

Figure 2. 25-hydroksyvitamin D [25(OH)D] levels in patients with single- or multivessel coronary artery disease measured during summer and winter.

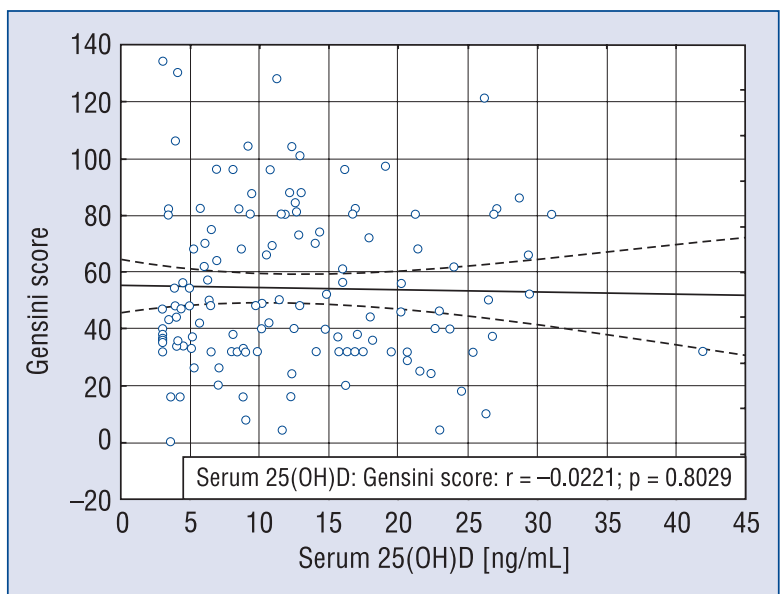

Figure 3. Correlation between vitamin D level and Gensini score in patients with acute myocardial infarction; 25(OH)D - 25-hydroksyvitamin D; r — Spearman's rank correlation coefficient.

In the multiple stepwise logistic regression analysis of $25(\mathrm{OH}) \mathrm{D}$ level, demographic (age, sex) and clinical risk factors (BMI, diabetes, hypertension, smoking status and total cholesterol concentration), diabetes revealed to be the only significant predictor of multi-vessel CAD (OR 1.9; 95\% CI 1.14-3.16; $\mathrm{p}=0.013)$. 


\section{Discussion}

Our study describes the vitamin D status in patients presenting the first STEMI. It confirms a highly prevalent deficiency of vitamin $\mathrm{D}$ in these patients. Only $2 \%$ of participants had sufficient levels of $25(\mathrm{OH}) \mathrm{D}$.

Lee et al. [21] have demonstrated similar results. Among 239 patients admitted with acute MI, $96 \%$ had abnormal 25(OH)D levels ( $\leq 30 \mathrm{ng} / \mathrm{mL}$ ), $75 \%$ were found to have $25(\mathrm{OH}) \mathrm{D}$ levels $\leq 20 \mathrm{ng} / \mathrm{mL}$, which is in the deficient range, $24 \%$ were in the insufficient range with vitamin D levels of $20 \mathrm{ng} / \mathrm{mL}$ to $30 \mathrm{ng} / \mathrm{mL}$ and only $4 \%$ had normal level with vitamin D levels $>30 \mathrm{ng} / \mathrm{mL}$. Mahdavi et al. [22] have also observed vitamin D deficiency in most patients with acute coronary syndrome. The proper $25(\mathrm{OH}) \mathrm{D}$ level was found only in $10.6 \%$ of 216 investigated patients (110 with STEMI, 106 with unstable angina/non-STEMI). Similar results were presented by Correia et al. [23]. Vitamin D sufficiency was diagnosed only in $10 \%$ of 216 patients with acute MI (7\% with STEMI). Serum 25(OH)D level $<20 \mathrm{ng} / \mathrm{mL}$ was present in $59 \%$ of participants. The above studies support our observation of a high prevalence of vitamin $\mathrm{D}$ deficiency in patients with MI.

The relationship between vitamin D levels and atherosclerosis has been inconclusive. Vitamin D levels have been correlated with other measures of subclinical atherosclerosis. Among 390 patients with type 2 diabetes, vitamin $\mathrm{D}$ concentrations were inversely correlated with carotid IMT of the common carotid artery [6]. The results of another study presents an association between serum vitamin D levels and internal carotid, but not with common carotid IMT [24].

The results of 2 studies: The Multi-Ethnic Study of Atherosclerosis (MESA) [25] and The Coronary Artery Calcification in Type 1 Diabetes (CACTI) [26] indicate that vitamin D deficiency may be of particular importance during the early events leading to the development but not to the progression of coronary calcification. The results suggest that lower vitamin D levels predicted coronary artery calcification, which is a sensitive measure of subclinical coronary atherosclerosis and a strong risk factor for cardiovascular events.

In our study no statistically significant correlation between $25(\mathrm{OH}) \mathrm{D}$ levels and severity of atherosclerosis in angiography was observed. There is a lack of data concerning this relationship in patients with STEMI. Although Correia et al. [23] in a comparable study have not evaluated the correlation between vitamin level and atheroscle- rosis severity, they have noticed the same mean value of Gensini score in patients both with severe $(<10 \mathrm{ng} / \mathrm{mL})$ and not severe $(>10 \mathrm{ng} / \mathrm{mL})$ vitamin $\mathrm{D}$ deficiency. Similar observations were reported in LURIC study [10]. Serum 25(OH)D levels were measured in 3,299 Caucasian patients who were routinely referred to coronary angiography. Concerning the vitamin level all patients were classified into four group ( $<10,10-20,20-30,>30 \mathrm{ng} / \mathrm{mL})$. The frequency of angiographically defined CAD was similar in all groups.

As opposed to our results, Akin et al. [27] have described significant correlation between serum $25(\mathrm{OH}) \mathrm{D}$ level and Gensini score measured in 239 patients with $\mathrm{CAD}$, who underwent coronary angiography. The relationship between vitamin $\mathrm{D}$ inadequacy and significant coronary artery stenosis was also found by Lim et al. [28]. The coronary artery calcium score and stenosis were evaluated using multidetector-row cardiac computed tomography.

On the basis of the results of the study we cannot determine whether levels greater than $30 \mathrm{ng} / \mathrm{mL}$ would be associated with greater atherosclerosis reduction. Recently, the US-Institute of Medicine has declared circulating 25(OH)D levels of $30 \mathrm{ng} / \mathrm{mL}$ sufficient to the health of general population [29]. There is no doubt that future studies are needed to obtain a better clarification of the physiologic range of vitamin $\mathrm{D}$ for preventing atherosclerosis and CVD.

\section{Limitations of the study}

Blood samples were drawn only once in our cohort. A single 25(OH)D measurement may not reflect lifetime vitamin D status. Small study group limited power of some analyses, thus their results cannot be extrapolated to the general population of patients with STEMI.

\section{Conclusions}

In conclusion, this study demonstrates - to our knowledge for the first time - that level $25(\mathrm{OH}) \mathrm{D}$ is not associated with the severity of coronary lesions on the angiogram of patients presenting with the first STEMI. We confirmed a high prevalence of vitamin D deficiency in patients with acute MI.

\section{Acknowledgements}

This study was supported by grant no. NN402504640 from the State Committee for Scientific Research, Poland.

Conflict of interest: none declared 


\section{References}

1. DeLuca HF. Overview of general physiologic features and functions of vitamin D. Am J Clin Nutr, 2004; 80: 1689-1696.

2. FormanJP,Bischoff-FerrariHA, WillettWC,StampferMJ,Curhan GC. Vitamin D intake and risk of incident hypertension: results from three large prospective cohort studies. Hypertension, 2005; 46: 676-682.

3. Pittas AG, Lau J, Hu FB, Dawson-Hughes B. The role of vitamin D and calcium in type 2 diabetes. A systematic review and metaanalysis. J Clin Endocrinol Metab, 2007; 92: 2017-2029.

4. Lamendola CA, Ariel D, Feldman D, Reaven GM. Relations between obesity, insulin resistance, and 25-hydroxyvitamin D. Am J Clin Nutr, 2012; 95: 1055-1059.

5. Ford ES, Ajani UA, McGuire LC, Liu S. Concentrations of serum vitamin $\mathrm{D}$ and the metabolic syndrome among U.S. adults. Diabetes Care, 2005; 28:1228-1230.

6. Targher G, Bertolini L, Padovani R et al. Serum 25-hydroxyvitamin D3 concentrations and carotid artery intima-media thickness among type 2 diabetic patients. Clin Endocrinol (Oxf), 2006; 65: 593-597.

7. Watson KE, Abrolat ML, Malone LL et al. Active serum vitamin D levels are inversely correlated with coronary calcification. Circulation, 1997; 96: 1755-1760.

8. Zittermann A, Koerfer R. Protective and toxic effects of vitamin D on vascular calcification: clinical implications. Mol Aspects Med, 2008; 29: 423-432.

9. Giovannucci E, Liu Y, Hollis BW, Rimm EB. 25-hydroxyvitamin D and risk of myocardial infarction in men: a prospective study. Arch Intern Med, 2008; 168: 1174-1180.

10. Pilz S, März W, Wellnitz B et al. Association of vitamin D deficiency with heart failure and sudden cardiac death in a large cross-sectional study of patients referred for coronary angiography. J Clin Endocrinol Metab, 2008; 93: 3927-3935.

11. Melamed ML, Michos ED, Post W, Astor B. 25-hydroxyvitamin $\mathrm{D}$ levels and the risk of mortality in the general population. Arch Intern Med, 2008; 168: 1629-1637.

12. Aihara K, Azuma H, Akaike M et al. Disruption of nuclear vitamin D receptor gene causes enhanced thrombogenicity in mice. J Biol Chem, 2004; 279: 35798-35802.

13. Nilsson J, Hansson GK. Autoimmunity in atherosclerosis: A protective response losing control? J Intern Med, 2008; 263: 464-478.

14. Libby P, Ridker PM, Hansson GK; Leducq Transatlantic Network on Atherothrombosis. Inflammation in atherosclerosis: From pathophysiology to practice. J Am Coll Cardiol, 2009; 54: 2129-2138.

15. Klingenberg R, Hansson GK. Treating inflammation in atherosclerotic cardiovascular disease: emerging therapies. Eur Heart J, 2009; 30: 2838-2844.
16. Lavie CJ, Milani RV, Verma A, O'Keefe JH. C-reactive protein and cardiovascular diseases: Is it ready for primetime? Am J Med Sci, 2009; 338: 486-492.

17. Takeda M, Yamashita T, Sasaki N et al. Oral administration of an active form of vitamin D3 (calcitriol) decreases atherosclerosis in mice by inducing regulatory $\mathrm{T}$ cells and immature dendritic cells with tolerogenic functions. Arterioscler Thromb Vasc Biol, 2010; 30: 2495-2503.

18. Thygesen K, Alpert JS, White HD; Joint ESC/ACCF/AHA/WHF Task Force for the Redefinition of Myocardial Infarction. Universal definition of myocardial infarction. Eur Heart J, 2007; 28: 2525-2538.

19. Gensini GG. A more meaningful scoring system for determining the severity of coronary heart disease. Am J Cardiol, 1983; 51: 606.

20. Holick MF, Binkley NC, Bischoff-Ferrari HA et al. Evaluation, treatment, and prevention of vitamin D deficiency: An Endocrine Society clinical practice guideline J Clin Endocrinol Metab, 2011; 96: 1911-1930.

21. Lee JH, Gadi R, Spertus JA, Tang F, O’Keefe JH. Prevalence of vitamin $\mathrm{D}$ deficiency in patients with acute myocardial infarction. Am J Cardiol, 2011; 107: 1636-1638.

22. Mahdavi K, Amirajam Z, Yazdankhah S et al. The prevalence and prognostic role of vitamin d deficiency in patients with acute coronary syndrome: A single centre study in South-West of Iran. Heart Lung Circ, 2012; doi: 10.1016/j.hlc.2012.11.006.

23. Correia L, Sodré F, Garcia G et al. Relation of severe deficiency of vitamin $\mathrm{D}$ to cardiovascular mortality during acute coronary syndromes. Am J Cardiol, 2013; 111: 324-327.

24. Reis JP, von Mühlen D, Michos ED et al. Serum vitamin D, parathyroid hormone levels, and carotid atherosclerosis. Atherosclerosis, 2009; 207: 585-590.

25. de Boer IH, Kestenbaum B, Shoben AB, Michos ED, Sarnak MJ, Siscovick DS. 25-hydroxyvitamin D levels inversely associate with risk for developing coronary artery calcification. J Am Soc Nephrol, 2009; 20: 1805-1812.

26. Young KA, Snell-Bergeon JK, Naik RG et al. Vitamin D deficiency and coronary artery calcification in subjects with type 1 diabetes. Diabetes Care, 2011; 34: 454-458.

27. Akin F, Ayca B, Kose N et al. Serum vitamin D levels are independently associated with severity of coronary artery disease. J Investig Med, 2012; 60: 869-873.

28. Lim S, Shin H, Kim MJ et al. Vitamin D inadequacy is associated with significant coronary artery stenosis in a community-based elderly cohort: The Korean Longitudinal Study on Health and Aging. J Clin Endocrinol Metab, 2012; 97: 169-178.

29. Ross AC, Taylor CL, Yaktine AL, Del Valle HB eds. Institute of Medicine (US) Committee to Review Dietary Reference Intakes for Vitamin D and Calcium. Dietary reference intakes for calcium and vitamin D. National Academies Press (US), Washington 2011: 370 . 